\title{
Avaliação do teste do anel em leite na vigilância epidemiológica da brucelose bovina em rebanhos e em laticínios
}

\author{
[Evaluation of the ring test in an epidemiological surveillance of bovine brucellosis in herds and dairies] \\ F.F. Silva Júnior ${ }^{1}$, J. Megid ${ }^{2}$, C.N. Nozaki ${ }^{1}$, J.P.A.N. Pinto ${ }^{2}$ \\ ${ }^{1}$ Aluno de pós-graduação - FMVZ-UNESP - Botucatu, SP \\ ${ }^{2}$ Faculdade de Medicina Veterinária e Zootecnia - UNESP \\ Caixa Postal 560 \\ 18618-000 - Botucatu, SP
}

\begin{abstract}
RESUMO
Analisaram-se 464 amostras individuais de leite e 54 amostras de leite de latões, oriundos de leite dos mesmos animais, por meio do teste do anel do leite (TAL) visando à sua aplicação no diagnóstico individual e de rebanhos da brucelose bovina. Foram também avaliadas 464 amostras de soro sangüíneo por meio de provas do antígeno tamponado acidificado (ATA), soroaglutinação lenta em tubos (SAL) e 2mercaptoetanol (2-ME), todas para brucelose. Cento e vinte e três amostras $(26,5 \%)$ testadas pelo TAL apresentaram resultados positivos. Dessas, 30 resultaram positivas ao ATA, 28 ao ATA, à SAL e ao 2ME e 18 à SAL. Das amostras positivas ao TAL, 95 pertenciam a animais sorologicamente negativos ao 2-ME, caracterizando $77,2 \%(95 / 123)$ das reações falso-positivas; dos resultados negativos ao TAL, 4 pertenciam a animais sorologicamente positivos, caracterizando $1,2 \%(4 / 341)$ de reações falso-negativas no TAL individual. Das 54 amostras de leite de latões analisadas pelo TAL, 17 foram consideradas positivas, das quais uma foi caracterizada como falso-positivo, pois todos os animais que a compunham foram negativos ao 2-ME. De 37 latões considerados negativos ao TAL, três continham leite de animais positivos ao 2-ME, caracterizando $8,1 \%$ de falso-negativos. O TAL individual demonstrou elevado percentual de resultados falso-positivos, enquanto o TAL em amostras de leite obtidas em latões detectou $84,2 \%$ de latões contaminados e $75 \%$ de rebanhos infectados.
\end{abstract}

Palavras-chave: bovino, brucelose, teste do anel do leite, vigilância epidemiológica

\begin{abstract}
The ring test (RT) was analyzed regarding its application for the individual and herd bovine brucellosis diagnoses. Individual samples of milk from 464 cows and 54 composite samples of milk bucket from these animals were evaluated. The results were analyzed considering the serological results obtained by the rose bengal (RBT), tube agglutination (TAT) and 2-mercaptoethanol (2-ME) tests. From the 464 individual milk samples analyzed by the RT, 123 (26.5\%) presented positive results. From those, 30 were positive only to the RBT, 28 by the RBT/TAT/2-ME and 18 by the TAT. From the 123 positive samples by the RT, 95 came from the 2-ME seronegative animals, characterizing $77.2 \%$ of false-positive reactions and 4/341 negative reactions came from the seropositive animals, characterizing $1.2 \%$ of false-negative reactions in the individual RT. From the 54 samples of compositive milk analyzed by the RT, 17 were positive. From these positive samples, one was considered false positive since all the animals that composed it were negative by the 2-ME. Three of the composite milk samples that were negative to $R T(3 / 37)$ were constituted by milk from positive animals, characterizing $8.1 \%$ of false-negative results by the RT. The individual RT showed high percentage of false-positive results, while the RT in samples from bucket detected $84.2 \%$ of the contaminated milk and $75 \%$ of the infected herds.
\end{abstract}

Keywords: bovine, brucellosis, ring test, epidemiological surveillance

Recebido em 21 de julho de 2004

Aceito em 21 de dezembro de 2006

E-mail: jane@fmvz.unesp.br 


\section{INTRODUÇÃO}

Um grande problema a ser enfrentado é o controle de determinadas zoonoses, transmitidas ao homem por meio do leite cru e seus derivados. Dentre essas enfermidades, destaca-se a brucelose, que ocorre endemicamente em todo o território nacional (Souza et al., 1977; Brucelose..., 1991).

A brucelose bovina é uma doença infecciosa de origem bacteriana causada, normalmente, por Brucella abortus que se caracteriza por abortos nos estágios finais da gestação e altas taxas de infertilidade (Alton et al., 1976). Os prejuízos econômicos são evidenciados pela queda na produção de leite e carne e redução da fertilidade, devido ao aumento significativo do número de vacas estéreis, e menor taxa de natalidade (Olascoaga, 1976). Pelo seu caráter zoonótico, torna-se de primordial importância a identificação e a eliminação das fontes de infecção com a finalidade de bloquear a transmissão ao ser humano e a outros animais susceptíveis (Nielsen et al., 1990).

Dado o impacto econômico na saúde animal e o risco de contaminação da população humana, diversos países têm aplicado recursos para diagnóstico, controle e erradicação da brucelose. Em 2000, no Brasil, foi lançado pelo Ministério da Agricultura e Abastecimento o Programa Nacional de Controle e Erradicação da Brucelose e Tuberculose (PNCEBT), com o objetivo de diminuir a prevalência e a incidência dessas enfermidades (Manual..., 2001). Quanto à brucelose, o regulamento do PNCEBT preconiza a vacinação das fêmeas de três a oito meses de idade, e o diagnóstico sorológico dos animais por meio das provas do antígeno acidificado tamponado e 2-mercaptoetanol (constituído pelas provas de soroaglutinação lenta e 2mercaptoetanol (SAL/2-ME) e o teste do anel em leite (TAL) para o monitoramento de estabelecimentos certificados como livres de brucelose (Manual, 2001). A aplicação dos testes diagnósticos em rebanhos e laticínios fornece o diagnóstico da situação e permite que sejam adotadas medidas de controle eficazes.

O objetivo do presente trabalho foi avaliar o teste do anel em leite como ferramenta de vigilância epidemiológica em amostras individuais de leite e em amostras de latões no laticínio.

\section{MATERIAL E MÉTODOS}

Foram analisadas 464 amostras individuais de leite e de soro sangüíneo de fêmeas bovinas em diferentes períodos de lactação, com idade variando de dois a 12 anos, provenientes de 13 propriedades do interior do estado de São Paulo, localizadas nos municípios de Botucatu, Pardinho e Pereiras. Foram, também, analisadas 54 amostras de leite dos latões constituídas por leite dos respectivos animais.

O tamanho da amostra foi calculado considerando um limite de confiança de 95\% e um erro de estimativa de prevalência de 5\% (Zar, 1996).

Após a anti-sepsia dos quartos do animal, e descarte dos três primeiros jatos de leite de cada quarto, foram colhidas, por ordenha manual, $10 \mathrm{ml}$ de amostras individuais de cada teto em tubos de ensaio plásticos estéreis. As amostras foram encaminhadas ao laboratório em caixas isotérmicas para realização do California Mastitis Test (CMT) e do teste do anel em leite (TAL). Todos os leites dos quartos foram analisados individualmente frente ao CMT; o TAL foi realizado apenas em um dos quartos, escolhido aleatoriamente por sorteio.

No laticínio, as amostras foram coletadas dos latões com o auxílio de uma pipeta estéril, aproximadamente $10 \mathrm{ml}$ de leite.

As amostras de sangue dos animais, dos quais se coletou o leite, obtidas por punção da veia mamária foram coletadas em tubos de ensaio de $10 \mathrm{ml}$, dos quais se obteve o soro, após centrifugação a $800 \mathrm{~g}$ durante oito minutos. Os soros foram transferidos para tubos ependorfes ${ }^{\circledR}$ estéreis e mantidos congelados a $-20^{\circ} \mathrm{C}$ até a realização dos testes sorológicos.

O CMT foi realizado de acordo com a técnica descrita por Schalm e Noorlander (1957), utilizando-se o reagente químico $\mathrm{CMT}^{1}$ para diagnóstico da mastite bovina. Os resultados foram classificados de acordo com o protocolo do fabricante, variando de negativo para leite sem precipitação a três cruzes para leite completamente coagulado ou gelatinoso. O TAL

${ }^{1}$ Fatec S.A. - São Paulo - Brasil 
foi realizado de acordo com a técnica descrita por Garcia-Carrilo (1982), modificado com base na metodologia descrita por Roepke e Stiles (1970). As amostras de leite coletadas na propriedade e no laticínio foram mantidas em refrigeração por, aproximadamente, seis horas, período relacionado ao transporte e, imediatamente, processadas ao chegarem ao laboratório. Após a homogeneização da amostra, $1 \mathrm{ml}$ do leite foi colocado em tubo de ensaio e a ele foi adicionado $0,03 \mathrm{ml}$ de antígeno, seguido por inversão lenta do tubo e incubação a $37^{\circ} \mathrm{C}$ por $1 \mathrm{~h}$. Amostras com anel de creme com tonalidade roxo azulado foram consideradas positivas (Brasil, 2001).

A prova do antígeno tamponado acidificado (ATA) foi realizada com base na metodologia de Mac Millan (1990). Foram consideradas como positivas as amostras que apresentaram aglutinação.

A soroaglutinação lenta em tubos (SAL) foi realizada de acordo com a técnica descrita por Alton et al. (1976). Foram consideradas como positivas as amostras que apresentaram uma película de aglutinação no fundo do tubo, sobrenadante límpido e formação de grumos ao serem levemente agitados. Nas amostras negativas, a coluna apresentou-se turva, com ou sem depósito, que se dissolveu após a leve agitação do tubo.

A metodologia do 2-mercaptoetanol (2-ME) foi baseada na técnica descrita por Alton et al. (1976). As amostras positivas foram interpretadas pela presença de aglutinação no fundo do tubo, sobrenadante límpido e formação de grumos ao serem levemente agitados. Nas amostras negativas, houve turvação, com ou sem depósito, que se dissolvia com agitação do tubo. Os resultados foram analisados considerando-se a prova de 2-ME como confirmatória no diagnóstico da brucelose animal de acordo com Brasil (2001).

Em todas as provas sorológicas e no TAL, foram utilizadas amostras de soro e leite positivas como controle da reação.

Para análise estatística, no TAL usou-se o teste de McNemar (ZAR, 1996). As propriedades classificadas como positivas e negativas para brucelose foram comparadas em relação à produção de leite pelo teste $\mathrm{t}$ de Student (ZAR, 1996) para amostras individuais. Para calcular a sensibilidade e a especificidade do TAL foram calculadas por meio do win episcope 2.0 (De Blas et al., 2000), tomando como base os resultados positivos no 2-ME.

\section{RESULTADOS E DISCUSSÃO}

Pelo CMT, 146 (31,5\%) animais foram positivos; destes $43(29,5 \%)$ eram submetidos à ordenha manual e $103(70,5 \%)$ à ordenha mecânica.

Os resultados obtidos na relação entre o TAL individual e o CMT são apresentados na Tab. 1.

Tabela 1. Resultados do teste do anel em leite (TAL) em 464 amostras individuais de leite bovino, dos quartos sorteados, associados aos resultados obtidos no California mastitis test (CMT)

\begin{tabular}{lccc}
\hline & TAL pos. & TAL neg. & Total \\
\hline CMT (neg.) & 86 & 232 & 318 \\
CMT(pos.) & 37 & 109 & 146 \\
Total & 123 & 341 & 464 \\
\hline
\end{tabular}

Pos= Positivo; neg $=$ negativo.

Das 123 amostras positivas ao TAL, 37 resultaram CMT positivo, das quais 21 pertenciam a animais com sorologia positiva e 16 a bovinos sorologicamente negativos, indicando possível interferência da mastite nos resultados do TAL em 13,0 \% dos leites analisados. Esses resultados são similares aos encontrados por Chielle et al. (1989) que obtiveram elevado percentual de reações falso-positivas no TAL em animais com CMT positivo e concluíram que a causa mais provável de resultados falsopositivos, no teste, seria a presença de leucócitos e células de descamação da glândula mamária no leite. Essa possibilidade foi confirmada por vários autores (Olascoaga, 1976; Nicoletti, 1994; Acedo et al., 1997) que correlacionaram reações falso-positivas à ocorrência de mastite.

Em 464 soros sangüíneos, $38 \quad(8,2 \%)$ apresentaram resultados positivos ao ATA e 32 $(6,9 \%)$ ao 2-ME em associação com a SAL. Estes últimos caracterizam os animais positivos na população estudada. Esse percentual de positividade é mais alto que o relatado por Poester et al. (2002), no Brasil, e se justifica por não representar dados de prevalência, mas 
somente de ocorrência da enfermidade nos rebanhos estudados.

Das $123(26,5 \%)$ amostras positivas ao TAL (Tab. 2), somente $28(22,8 \%)$ procediam de animais que resultaram positivos ao ATA/SAL/2-ME. Das amostras positivas ao TAL individual, $27 \quad(21,9 \%)$ e $3 \quad(2,4 \%)$ procediam de animais que resultaram sorologicamente positivos à SAL e ao ATA/SAL, e ambas negativas ao 2-ME. Considerando a inativação da $\operatorname{IgM}$ pelo 2-ME (Nielsen et al., 1990), esses resultados sugerem que essas reações podem ser atribuídas à presença de IgM, uma vez que essa imunoglobulina, juntamente com a IgA, é uma das responsáveis pelas reações positivas no TAL (Sutra et al.,1986; Lopez et al., 1998).

Tabela 2. Resultados do teste do anel em leite (TAL) em 464 amostras de leite individual, associados aos resultados sorológicos

\begin{tabular}{lccc}
\hline Sorologia & TAL pos. & TAL neg. & Total \\
\hline SAL neg. 2-ME neg. & 65 & 334 & 399 \\
SAL pos. 2-ME neg & 27 & 0 & 27 \\
ATA/SAL pos. 2-ME neg. & 3 & 3 & 6 \\
ATA/SAL/2-ME pos. & 28 & 4 & 32 \\
Total & 123 & 341 & 464 \\
\hline
\end{tabular}

$\mathrm{ATA}=$ antígeno acidificado tamponado; $\mathrm{SAL}=$ soroaglutinação lenta em tubos; $2-\mathrm{ME}=2$-mercaptoetanol, pos. $=$ título $\geq 25$.

Quando se consideram os resultados globais, observa-se que 95 amostras pertenciam a animais sorologicamente negativos ao ATA/SAL e/ou ao 2-ME e quatro, das 341 amostras negativas ao TAL, pertenciam aos sorologicamente positivos ao ATA/SAL/2-ME, caracterizando $77,2 \%$ das reações falso-positivas e 1,2\% de reações falsonegativas ao TAL individual.

Resultados negativos no TAL individual foram obtidos em quatro $(0,9 \%)$ animais que apresentaram títulos sorológicos de 50 e 200 à SAL e 2-ME, respectivamente. Resultados negativos no teste foram observados por Tomé e Samartino (1997), ao verificarem dois animais negativos ao TAL entre os 15 sorologicamente positivos. Os autores consideraram o TAL muito útil na vigilância epidemiológica das áreas livres, porém, para determinar animais individuais e/ou propriedades infectadas por brucelose, consideraram seus resultados variáveis e dependentes de alguns fatores como período de eliminação e quantidade de anticorpos presentes no leite de animais infectados, tamanho da propriedade e freqüência com que se realiza o controle do rebanho.

O TAL realizado em amostras individuais de leite apresentou sensibilidade de 87,5\%, resultado similar ao encontrado por Zoghi et al. (1992), que detectaram 1632 amostras de leite positivas ao TAL dentre 1956 animais sorologicamente positivos, caracterizando $83,4 \%$ de sensibilidade.
A especificidade do TAL em amostras individuais foi de $78 \%$, diferente do resultado observado por Huber e Nicoletti (1986), que ao avaliarem o TAL em 1003 amostras individuais de leite, caracterizaram especificidade de 57,5\%. A discrepância pode ser justificada pelos diferentes métodos utilizados para definição da especificidade, uma vez que esses autores avaliaram a técnica frente à fixação de complemento. Baixa especificidade do TAL em amostras individuais de leite foi, também, descrita por Olascoaga (1976) e por Heck et al. (1980), os quais consideraram que, em função da baixa especificidade do teste individual, os animais positivos ao TAL deveriam ser reavaliados em outras provas sorológicas.

Cinqüenta latões com 50 litros e quatro com 25 a 30 litros continham leite de, no mínimo, três e, no máximo, 19 animais. Dessas 54 amostras de leite, $16(29,6 \%)$ foram positivas ao TAL. Nelas havia leite de animais sorologicamente positivos à $\mathrm{SAL}$ e ao 2-ME. Um (1,8\%) resultou positivo ao TAL, porém, todos os animais que a compunham resultaram negativos à SAL e ao 2ME. Três $(5,6 \%)$ latões foram classificados como TAL negativos, todavia, possuíam leite de animais positivos à SAL/2-ME, caracterizando falsos negativos (Tab. 3). 
Tabela 3. Resultados do teste do anel em leite (TAL) em 54 amostras de leite em latões comparativamente à classificação sorológica individual dos animais que compunham o latão. Botucatu-SP, 2003

\begin{tabular}{lccc}
\hline Sorologia & $\begin{array}{c}\text { TAL } \\
\text { pos. }\end{array}$ & TAL neg. & Total \\
\hline $\begin{array}{l}\text { Positivo SAL/2ME } \\
\text { pos. }\end{array}$ & 16 & 3 & 19 \\
$\begin{array}{l}\text { Negativo SAL/2ME } \\
\text { neg. }\end{array}$ & 1 & 34 & 35 \\
Total & 17 & 37 & 54 \\
\hline
\end{tabular}

$\mathrm{SAL}=$ soroaglutinação lenta em tubos, $2-\mathrm{ME}=2$ mercaptoetanol.

Dezenove latões eram compostos por leite de animais positivos, caracterizando $35,2 \%$ de latões contaminados. O TAL detectou $16(84 \%)$ latões contendo leite contaminado, pertencente a seis propriedades, representando $75 \%$ do total de propriedades com animais brucélicos. Estes resultados confirmam o TAL como importante método de vigilância epidemiológica e concordam com a OIE (Bovine..., 2000), que indica seu uso para amostra de leite em latões/tanques compostas por leite de até 100 animais.

O TAL detectou um animal positivo com título sorológico na SAL e 2-ME de 200 e 100, respectivamente, entre outros 18 animais sorologicamente negativos no latão. Foram observados resultados falso-negativos em latões com pool de leite - um mínimo de seis e um máximo de 12 animais, e títulos que variaram de 50 a 200 e 25 a 200, respectivamente, na SAL e 2-ME em ambos os testes. Os resultados falsonegativos confirmam os de Tomé e Samartino (1997), em que a eficácia do TAL, para detectar animais ou rebanhos infectados por brucelose, é variável e depende de fatores como a eliminação ou não de anticorpos brucélicos pelo leite. Garcia-Carrillo (1982) relataram a existência de vacas infectadas que não eliminavam anticorpos pelo leite.

Um resultado falso-positivo foi observado em amostras de leite em latão compostas por leite de sete animais, dos quais um apresentava reação positiva ao ATA e SAL, demonstrando a possibilidade de reação decorrente de IgM (Sutra et al., 1986; Lopez et al., 1998). Seis amostras apresentaram resultados duas cruzes ou mais no
CMT, sugerindo a interferência da mastite no teste, conforme o relatado por (Olascoaga (1976); Nicoletti (1994); Acedo et al. (1997).

A ocorrência de resultados falso-positivos em latões foi mais baixa que a obtida por Rolfe e Sykes (1987), que obtiveram 3,7\% de reações falso-positivas em latões, o que pode ser explicado pela ausência de animais vacinados com $\mathrm{B}_{19}$ neste estudo, diferente do estudo realizado pelos autores citados.

O TAL em amostras de latões foi capaz de detectar $75 \%$ das propriedades sorologicamente positivas, resultados próximos aos relatados por Morgan (1967), que diagnosticou 75\% de rebanhos infectados, porém, com três testes consecutivos.

O teste do anel em leite em latões, no entanto, não foi capaz de detectar duas $(25 \%)$ das propriedades infectadas, demonstrando a necessidade de testes sorológicos adicionais, aspecto já relatado por Tomé e Samartino (1997).

Os resultados do TAL em amostras de leite de latões caracterizaram uma sensibilidade de $84,2 \%$ e uma especificidade de 97,1\%, demonstrando ser um bom método diagnóstico presuntivo da brucelose bovina.

\section{CONCLUSÕES}

Os resultados demonstraram que o teste do anel em leite, realizado com amostras de leite de latões, é uma importante ferramenta de vigilância epidemiológica da brucelose bovina, indicada como método de diagnóstico presuntivo. Contudo, é fundamental realizar o diagnóstico sorológico individual nos programas de erradicação ou controle da enfermidade no rebanho. O teste do anel em leite em amostras individuais não se justifica pelo elevado percentual de resultados falso-positivos observados.

\section{REFERÊNCIAS BIBLIOGRÁFICAS}

ACEDO, E.; DÍAS, M.E.; LEÓN A.B. Incidencia de Brucella sp en leche cruda y queso fresco regional. Alimentaria, v.34, p.57-60, 1997. 
ALTON, G.G.; JONES, L.M.; PIETZ, D.E. Las técnicas de laboratorio de la brucelosis. Genebra: WHO, 1976. p.68-133 (OMS Série Monográfica, v.55).

MANUAL Técnico do Programa Nacional de Controle e Erradicação da Brucelose e Tuberculose - PNCEBT: legislação. Brasília: Secretaria de Defesa Agropecuária - MAPA, 2001. 47p

CHIELLE, L.L.; WEIBLEN, B.; MOREIRA, W. S. et al. Especificidade da prova do anel de leite (PAL) para o diagnóstico da brucelose bovina na bacia leiteira do município de Santa Maria - RS, Brasil. Rev. Centro Ciên. Rurais, v.19, p.351358, 1989.

DE BLAS, N.; ORTEGA, C.; FRANKENA, K. et al. Win Episcope 2.0. Zaragoza: CLIVE, 2000. Disponível em:

$<$ http://www.clive.ed.ac.uk/winepiscope $>$.

Acessado em: 11 out. 2003.

GARCIA-CARRILLO, C. Pruebas suplementarias para el diagnostico de la brucelosis. Nota Tec. Cent. Panam. Zoon., n.25, p.5-19, 1982.

HECK, F.C.; WILLIAMS, J.D.; PRUETT, J. et al. Enzyme-linked immunosorbent assay for detecting antibodies to Brucella abortus in bovine milk and serum. Am. J. Vet. Res., v.41, p.2082-2084, 1980.

HUBER, D.J.; NICOLETTI, P. Comparation of the results of card, rivanol, complement-fixation, and milk ring tests with the isolation rate of Brucella abortus from cattle. Am. J. Res., v.47, p.1529-1531 1986.

LOPEZ, J.; BEST, A.; MORALES, C. Diagnóstico de brucelosis bovina en leche por el ring test y ELISA en lecherías de la provincia de Nuble (VIII Región). Arch. Med. Vet., v.30, p.133-138, 1998 .

MAC MILLAN, A. Conventional serological test. In: NIELSEN, K.; DUNCAN, R. Animal brucellosis. Boca Raton: CRC, 1990. cap.8, p.153-198.

BRUCELOSE bovina. Bol. Def. Sanit. Anim., v.27, p.41-47, 1991.

MORGAN, W.J.B. The serological diagnosis of bovine brucellosis. Vet. Rec., v.80, p.612-621, 1967.
NICOLETTI, P. Epidemiología, patogenia y cuadro clínico. Bovis, v.57, p.17-25, 1994.

NIELSEN, K.; DUNCAN, J.R. Animal Brucellosis. Boca Raton: CRC, 1990. 453p.

BOVINE Brucellosis. In:_. Manual standarts diagnostic tests vaccines. Paris, 2000. Disponível em:

$<\mathrm{http}$ //www.oie.int/eng/maladies/fiches/A_B103 .htm> Acessado em: 10 nov. 2000.

OLASCOAGA, C.R. Diagnóstico serológico de la brucelosis. Zoonosis, v.18, p.107-141, 1976.

POESTER, F.P.; GONÇALVES, V.S.P.; LAGE, A.P. Brucellosis in Brazil. Vet. Microbiol., v.90, p.55-62, 2002.

ROEPKE, M.H.; STILES JR.; F.C. Potential efficiency of milk ring test for detection of brucellosis. Am. J. Vet. Res., v.31, p.2145-2149

ROLFE, D.C.; SYRES, W.E. Monitoring of dairy herds for Brucella abortus infection when prevalence is low. Aust. Vet. J., v.64, p.97-100, 1987

SCHALM, O.W.; NOORLANDER, D.O. Experiments and observation leading to development of California Mastitis Test. J. Am. Vet. Assoc., v.130, p.199-204, 1957.

SOUZA, A.P.; MOREIRA FILHO, D.C.; FÁVERO, M. Investigação da brucelose em bovinos e em consumidores humanos de leite. Rev. Saúde Públ., v.11, p.238-247, 1977.

SUTRA, L.; CAFFIN, J.P.; DUBRAY, G. Role of milk immunoglobulins in the Brucella milk ring test. Vet. Microbiol., v.12, p.359-366, 1986.

TOMÉ, J.G.; SAMARTINO, L.E. Eficacia de la prueba del anillo en la leche para el control y erradication de la brucelosis bovina. Vet. Argent., v.14, p.449-459, 1997.

ZAR, J.H. Bioestatistical analysis. New Jersey: Prentice-Hall, 1996. 718p.

ZOGHI, E.; EBADI, A.; MOHSENI, B. Isolation of Brucella organisms from the milk of seronegative cows. Arch. Inst. RAZI, v.42/43, p.35-38, 1992. 